\title{
Pyocyanin Assisting Biosurfactant Mediated Anti-shrimp Pathogen Activity and Crude Oil Recovery
}

\author{
Sriram Shankar, Ekramul Haque*, Saqib Hassan \\ Department of Microbiology, School of Life Sciences, Pondicherry University, Puducherry, INDIA.
}

\begin{abstract}
Background: The unflagging engrossing biosurfactant, representing ecological substitute to their synthetic equivalent has gained enormous attention in the $21^{\text {st }}$ century and their potential applicability in food, medicine and petrochemical industries is being explored and expanding. Objectives: The current study deals with the applicability of pyocyanin and biosurfactant in crude oil recovery and use as a potential anti-shrimp pathogen agent. Materials and Methods: The bacterial strain Pseudomonas aeruginosa ENO-14 was explored for their biosurfactant production using Luria Bertani Broth and Bushnell-Haas Broth supplemented with 1\% glucose under shaking condition and pyocyanin production using Luria Bertani Broth under static and shaking conditions. The highest concentration of biosurfactant $(11.07 \pm 0.15 \mathrm{mg} / \mathrm{ml})$ was obtained after $48 \mathrm{~h}$ at $37^{\circ} \mathrm{C}$ in 200 $\mathrm{rpm}$ and the maximum production of pyocyanin $(70.12 \pm 2.11 \mu \mathrm{g} / \mathrm{ml})$ was observed after $96 \mathrm{~h}$ at $37^{\circ} \mathrm{C}$ under static condition. Further Emulsification activity was evaluated using cell-free supernatant, biosurfactant alone and a combination of pyocyanin $(0.01 \%)$ and biosurfactant $(0.1 \%)$. Finally, the produced pyocyanin and biosurfactant were used as anti-shrimp pathogen activity by agar well diffusion assay and in crude oil recovery by sand pack column. Results: $100 \%$ emulsification were observed for
\end{abstract}

the crude oil when treated with pyocyanin and biosurfactant in a union The noteworthy outcome of this experiment is the prominent role played by pyocyanin in enhancing the emulsification of hydrocarbons. Moreover, as a novel observation, there was an additional significant increase $(80 \%)$ of residual oil recovered by sand pack column when both pyocyanin and biosurfactant were tested in conjunction as compared to the recovery obtained when biosurfactant was administered alone (65\%). Furthermore, both the compounds exhibited significant anti-shrimp pathogen activity. Conclusion: Therefore, biosurfactant and pyocyanin could have promising applications in the aquaculture and petrochemical industries.

Keywords: Biosurfactant, Pyocyanin, Emulsification activity, Oil recovery, Anti-shrimp pathogen activity.

Correspondence

Mr. Ekramul Haque

Senior Research Fellow(SRF), Department of Microbiology, School of Life Sciences, Pondicherry University, Puducherry-605014, INDIA.

Phone no: +91-8903947795

Email: hekramul37@gmail.com

DOI: 10.5330/ijpi.2020.4.100

\section{INTRODUCTION}

Surface active agents produced by microbes, assigned as biosurfactants have a broad range of applications in Environment, ${ }^{1,2}$ Petroleum, Mining, Medicine, Agriculture industries as well as in cosmetics and textile industries. ${ }^{3}$ They have a compelling influence on wettability alteration as a consequence of their ability to minimize surface and interfacial tensions. Notably, amidst all the biological products, biosurfactant has been extensively studied by many scientists as a result of their exceedingly valuable characteristics including stability, low toxicity and biodegradability and especially in a substantial effect on wettability alteration which naturally augment the eventual oil recovery. Rhamnolipids are undoubtedly the best-known biosurfactant, a major source of this Glycolipid Biosurfactant is Pseudomonas aeruginosa. ${ }^{4}$ Even though their pathogenic characteristic is questioned and debated, their use in addressing environmental concerns is of immense value. A typical example is that biosurfactants have a higher effective concentration in residual oil recovery than other biosurfactants such as lipopeptides. ${ }^{5}$ Furthermore, Biosurfactants are recognized as potential antimicrobial agents against several pathogens. ${ }^{6,7}$

Pseudomonas aeruginosa also can produce phenazine redox-active compound referred to as Pyocyanin, aerugo in Latin reflects verdigris, the Blue-Green layer on copper that flourish when it is exposed to air or seawater. ${ }^{8}$ Pyocyanin is widely understood as a virulence factor that has antimicrobial activity by the generation of reactive oxygen species. ${ }^{9}$ Moreover, it has been reported that pyocyanin produced by Pseudomonas aeruginosa of environmental origin has the potential to control pathogenic vibrios ${ }^{10-12}$ and boost larval survival in shrimp hatcheries. ${ }^{13}$ Recently pyocyanin was reported to have an influence on biosurfactant in enhancing hydrocarbon emulsification. ${ }^{14}$ The high molecular weight of biosurfactants can be attributed to their efficiency in emulsification and can be used as additives to trigger hydrocarbon bioremediation and their removal. ${ }^{15}$

Nowadays, the concern pertinent to the possibility of water and soil contamination by oil and it's by-products is rising especially due to setback in the transportation of fuel by ships, trucks, leakages from underground storage tanks, oil extraction, processing and inept in the release of oily waste provoked by industries that use oil and its by-products for the production of cosmetics, plastics and solvents. ${ }^{16}$ Moreover, after primary and secondary recoveries about $35-55 \%$ of crude oil is left behind ${ }^{17}$ that must be recovered by distinct upgraded or enhanced oil recovery such as polymer flooding, miscible gas injection and thermal enhanced oil recovery methods. Nevertheless, limitations such as production cost and environmental impacts still need to be addressed for these physical and chemical-based oil recoveries. Thus microbial enhanced oil recovery becomes handy as a tertiary oil recovery technique as it utilizes the help of micro-organisms and their products to recover oil either by 1) Injection of Micro-organisms (in-situ), 2) addition of nutrients to encourage indigenous micro-organism and 3) ex-situ production and their administration to the recovery site. ${ }^{18,19}$ The outcome of laboratory-scale simulated studies on the emulsification index and the residual oil recovery from the sand pack column recommends 
that biosurfactants are suitable applicants for enhanced oil recovery. ${ }^{20-21}$ Although Biosurfactants are utilized for enhanced oil recovery, to date there is no recorded literature depicting the combined enhancement of oil recovery using Pyocyanin, although a recent study has highlighted the combinatorial role of Pyocyanin and Biosurfactant in enhancing Hydrocarbon Emulsification. ${ }^{14}$

Therefore, the objective of this study is to observe the production kinetics of biosurfactant and pyocyanin and emphasize the prominent role played by pyocyanin at the Laboratory scale in Hydrocarbon emulsification and biosurfactant mediated enhanced oil recovery using sand pack column. Furthermore, their combinatorial role was assessed against potential shrimp pathogen Vibrio parahemolyticus by well diffusion assay.

\section{MATERIALS AND METHODS}

\section{Micro-organism, Media and Culture conditions}

Pseudomonas aeruginosa ENO-14 was already isolated, stored in a Cryo vial (a specialized preservation system) for microbiological cultures in our laboratory. The GenBank database accession number of this strain is MH271625. The isolate was revived from glycerol stock on LB agar plates. The inoculum was prepared on Luria Bertani Broth by incubating at $37^{\circ} \mathrm{C}$ for $16 \mathrm{~h}$ with an agitated speed of $200 \mathrm{rpm}$ and was then transferred to Bushnell-Haas medium supplemented with $1 \%$ glucose as a Carbon source and to Luria Bertani Broth for biosurfactant production as well as for pyocyanin production respectively. All the media were incubated for seven days and were systematically analysed for both pyocyanin and biosurfactant production at regular intervals of $24 \mathrm{~h}$. An uninoculated medium was also kept as control. Another experimental setup was carried out for pyocyanin Production under static condition, to compare the yield of Pyocyanin under both static and shaking conditions.

\section{Evaluation of Bacterial Growth and Biosurfactant Production}

The Production media containing the fermented broth samples were collected every day for about a week and the biomass was ascertained by the dry weight method as well as calculating the Optical density of the collected sample at $600 \mathrm{~nm}$ using UV Visible Spectrophotometer. Subsequently, the culture was observed for their stable froth that confirms Biosurfactant production. Partial Purification of biosurfactant was done by the solvent extraction method. ${ }^{22,23}$ Briefly, after centrifuging and collecting the cell free supernatant, acid precipitation was done at pH 2.0 using $6 \mathrm{~N} \mathrm{HCl}$ followed by extraction using an equal volume of ethyl acetate. Further, the organic solvent was evaporated using Rotary vacuum evaporator and the biosurfactant yield was determined gravimetrically and used for further experimental studies.

\section{Pyocyanin Extraction and Estimation}

The redox-active phenazine compound pyocyanin was extracted using chloroform as solvent by following the solvent extraction protocol as described by Saha et al. ${ }^{24}$ Further the quantitative estimation was done by measuring the acidified aqueous solution at $520 \mathrm{~nm}$ and was calculated using the following formula..$^{25,26}$

Concentration of Pyocyanin $(\mu \mathrm{g} / \mathrm{ml})=$ O.D $_{520} \times 17.072$

\section{Emulsification analysis}

The Emulsification index specifies instantaneous and decisive measures to quantify biosurfactants. The $\mathrm{E}_{24}$ was determined as detailed by Nitschke and Pastore. ${ }^{27}$ A solution was made by dissolving the dried biosurfactant with distilled water and was used for emulsification of liquid hydrocarbons petrol, diesel, kerosene, crude oil, gingelly oil, groundnut oil, almond oil, castor oil and sunflower oil. The Emulsification index was calculated by blending equal volume of aqueous cell free supernatant and hydrocarbons, vortexing at maximum speed for 5 mins followed by the incubation of the resulting mixture for $24 \mathrm{~h}$ and then the emulsification index was estimated using the equation

$\mathrm{E}_{24}=$ (height of the emulsion layer/ height of the total mixture) $\times 100$

The hydrocarbons kerosene, petrol and crude oil were also tested for their emulsification using both pyocyanin $(0.01 \%)$ and partially purified biosurfactant $(0.1 \%)$.

\section{Oil Recovery by Sand Pack Column}

The biosurfactant mediated oil recovery was examined by the Sand Pack column method. ${ }^{22,23}$ Acid washed pre-treated sand almost 120 $\mu \mathrm{m}$ grain size was saturated with $25 \mathrm{ml}$ of crude oil (Engine oil) in an upright glass column (Total volume $75 \mathrm{ml}$ ). The capability of the partially purified biosurfactant for oil recovery was measured by pouring $25 \mathrm{ml}$ of biosurfactant $(0,1 \%)$ within the glass column and the leftover residual oil liberated from the sand pack column was estimated. Furthermore, another experimental setup examining the capability of pyocyanin in assisting biosurfactant mediated oil recovery was tested. $25 \mathrm{ml}$ of partially purified biosurfactant (1\%) and pyocyanin $(0.1 \%)$ were poured and the remaining residual oil was measured. a

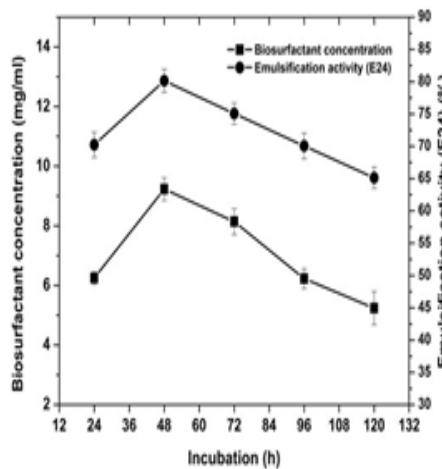

b

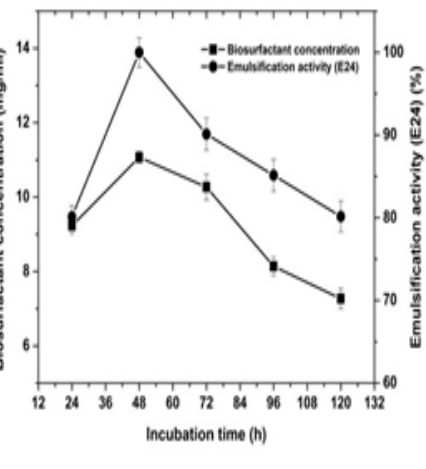

Figure 1: (a) Biosurfactant concentration obtained using Luria Bertani Broth and their Emulsification activity at 24h. (b) Biosurfactant concentration obtained using Bushnell Haas Medium and their Emulsification activity at 24h. All the analysis were carried out in triplicate. The values were presented as mean \pm SD $(n=3)$ a

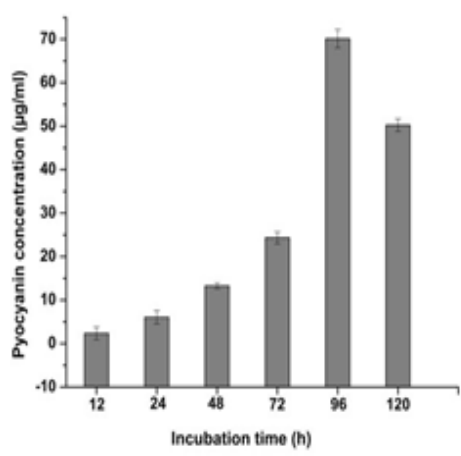

b

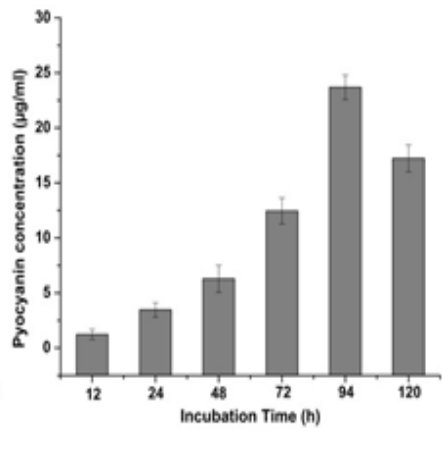

Figure 2: (a) Pyocyanin concentration obtained using Luria Bertani broth under static condition. (b) Pyocyanin concentration obtained using Luria Bertani broth under shaking condition. All the analysis were carried out in triplicate. The values were presented as mean \pm SD $(n=3)$ 


\section{Anti-shrimp pathogen capacity of biosurfactant and pyocyanin}

The isolated biosurfactant was analyzed for their antibacterial characteristics against a potential shrimp pathogen Vibrio parahemolyticus. The antibacterial activity was examined using the well diffusion test. Overnight cultures of Vibrio parahemolyticus were inoculated onto Luria Bertani agar $+2 \% \mathrm{NaCl}$ agar plates by flooding onto their surface and spreading them evenly. The wells were bored on the surface using a well borer and were treated with $50 \mu \mathrm{l}$ $(0.1 \%)$ of biosurfactant, $50 \mu \mathrm{l}$ of pyocyanin $(0.01 \%)$ and $25 \mu \mathrm{l}$ each of pyocyanin $(0.01 \%)$ and biosurfactant $(0.1 \%)$ onto different wells followed by their incubation at $37^{\circ} \mathrm{C}$ for $24 \mathrm{~h}$ and measuring the zone of inhibition formed around the well. The test was executed as triplicates.

\section{RESULTS}

\section{Analysis of Biosurfactant and Pyocyanin Production by Pseudomonas aeruginosa ENO 14}

Primary confirmation of biosurfactant production and pyocyanin production was ascertained by the observation of foam formation (Supplementary Figure 1a) and green pigmentation in the culture media (Supplementary Figure 1b). Moreover, the production of biosurfactants differed to the culture media used. Maximum biosurfactant concentration $(11.07 \pm 0.15 \mathrm{mg} / \mathrm{ml})$ was estimated after $48 \mathrm{~h}$ when $\mathrm{LB}$ broth was used with $5 \%$ inoculum $\left(10^{8} \mathrm{cfu}\right)$ at $37^{\circ} \mathrm{C}$ and $200 \mathrm{rpm}$ (Figure 1a) in comparison with the concentration estimated when the same conditions were maintained using $\mathrm{BHB}+1 \%$ Glucose $(9.23 \pm 0.38 \mathrm{mg} / \mathrm{ml})$ (Figure $1 \mathrm{~b}$ ). Pyocyanin production differed concerning the condition maintained at incubation. The Pigment production was at its best when the culture was incubated under the static condition with a maximum concentration of $70.12 \pm 2.11 \mu \mathrm{g} / \mathrm{ml}$ at $96 \mathrm{~h}$ (Figure $2 \mathrm{a}$ ), on the other hand, a maximum concentration of $23.68 \pm 1.11 \mu \mathrm{g} / \mathrm{ml}$ was calculated at $96 \mathrm{~h}$ under shaking condition (Figure 2b)

The bacterial strain Pseudomonas aeruginosa ENO-14 produced a significant amount of Pyocyanin Pigment in LB medium. The concentration of pyocyanin increased with time and the highest concentration was observed at $96 \mathrm{~h}(70.12 \pm 2.11 \mu \mathrm{g} / \mathrm{ml})$ under static condition (Figure $2 \mathrm{a}$ ) in comparison with the pyocyanin yield $(23.68 \pm 1.11$ $\mu \mathrm{g} / \mathrm{ml}$ ) under shaking condition (Figure $2 \mathrm{~b}$ ). Moreover, there was a drop in the concentration at $120 \mathrm{~h}$ at both conditions (Figure 2a, 3b).

\section{Emulsification Analysis}

Emulsification activity of ENO-14 Cell free supernatant with distinct hydrophobic compounds such as petrol, crude oil, kerosene, olive oil, gingelly oil, groundnut oil, almond oil, castor oil and sunflower oil was investigated (Figure 3). Among the tested hydrocarbons, crude oil showed the highest emulsification $(76.85 \pm 2.13 \%)$ followed by kerosene $(72.46 \pm 2.67 \%)$, the least emulsification activity was observed against almond oil (32.18 $\pm 1.97 \%)$. Further, ENO-14 showed good emulsification activity against petrol $(67.68 \pm 2.59 \%)$, groundnut oil $(61.55 \pm 2.93 \%)$, sunflower oil $(54.87 \pm 1.89 \%)$, olive oil $(52.68 \pm 2.33)$ and castor oil $(50.78 \pm 2.65 \%)$ and gingelly oil $(48.76 \pm 2.74 \%)$. All the tested hydrophobic substrates showed stable emulsions after $24 \mathrm{~h}$.

Another experimental setup examining the efficiency of emulsification by partially purified biosurfactant $(1 \mathrm{mg} / \mathrm{ml})$ alone and the combinatorial effect of biosurfactant $(0.1 \%)$ and pyocyanin pigment $(0.01 \%)$ respectively against petrol, crude oil and kerosene hydrocarbons was evaluated. Partial emulsification of hydrocarbons was observed when biosurfactant was used alone (Figure 4a), whereas complete emulsification was found when treated with the combination of biosurfactant and pyocyanin (Figure 4b).

\section{Microbial enhanced oil recovery (MEOR) from Sand Pack}

Biosurfactant was assessed for oil recovery and mobilization on acid cleaned, mesh sand saturated with crude oil (engine gear oil). At room temperature ENO-14 recovered $65 \%$ of crude oil from the sand pack column (Table 1).Significantly, another experimental setup testing the role of pyocyanin in assisting biosurfactant mediated oil recovery was elucidated. As hypothesized, there was a significant increase in the residual oil recovery $(80 \%)$ than that of biosurfactant alone (65\%) (Table 1).

\section{Biosurfactant and pyocyanin as an anti-shrimp pathogen agent}

The test biosurfactant and pyocyanin purified from the culture Pseudomonas aeruginosa ENO-14 demonstrated antimicrobial activity against notorious shrimp pathogen Vibrio parahemolytics. The characteristics of pyocyanin as a potential antibacterial agent got

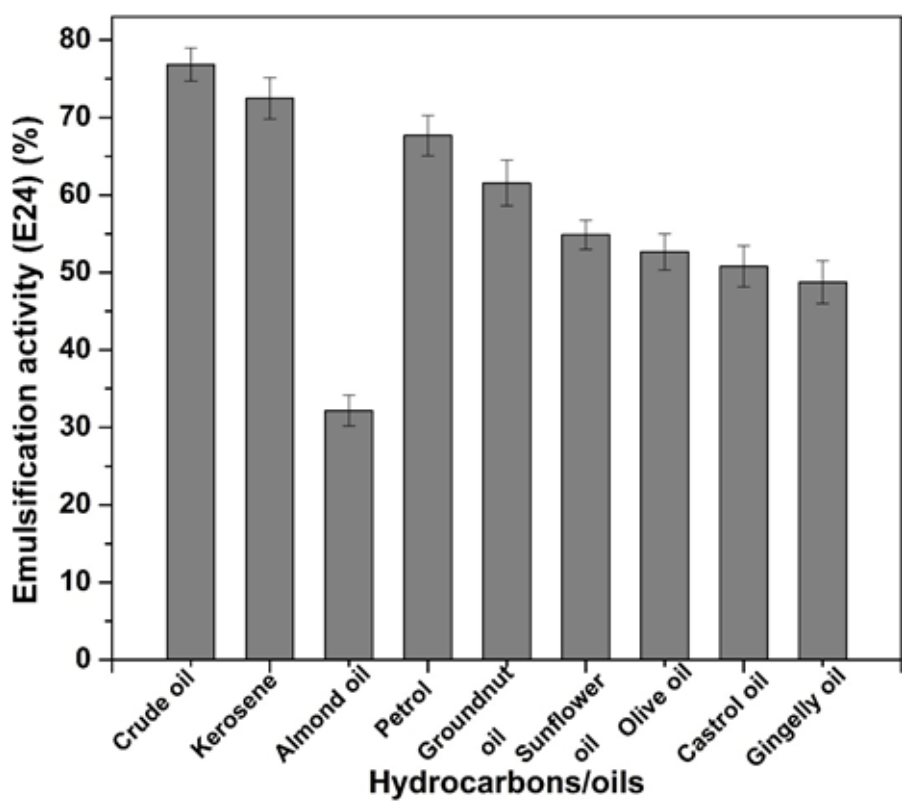

Figure 3: Emulsification activity of cell free supernatant obtained from Luria Bertani broth on various Hydrocarbons/oil. All the analysis were carried out in triplicate. The values were presented as mean \pm SD $(n=3)$

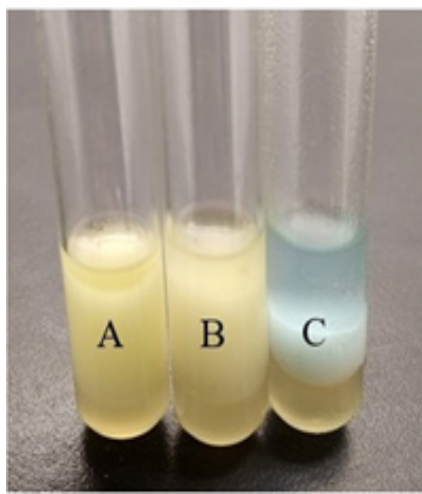

Figure 4: (a) Partial emulsification of Hydrocarbons A) Crude oil B) Petrol C) Kerosene using partially purified biosurfactant alone. (b) Complete Emulsification of Hydrocarbons A) Crude oil B) Petrol C) Kerosene using partially purified biosurfactant and pyocyanin. All the analysis were carried out in triplicate. 


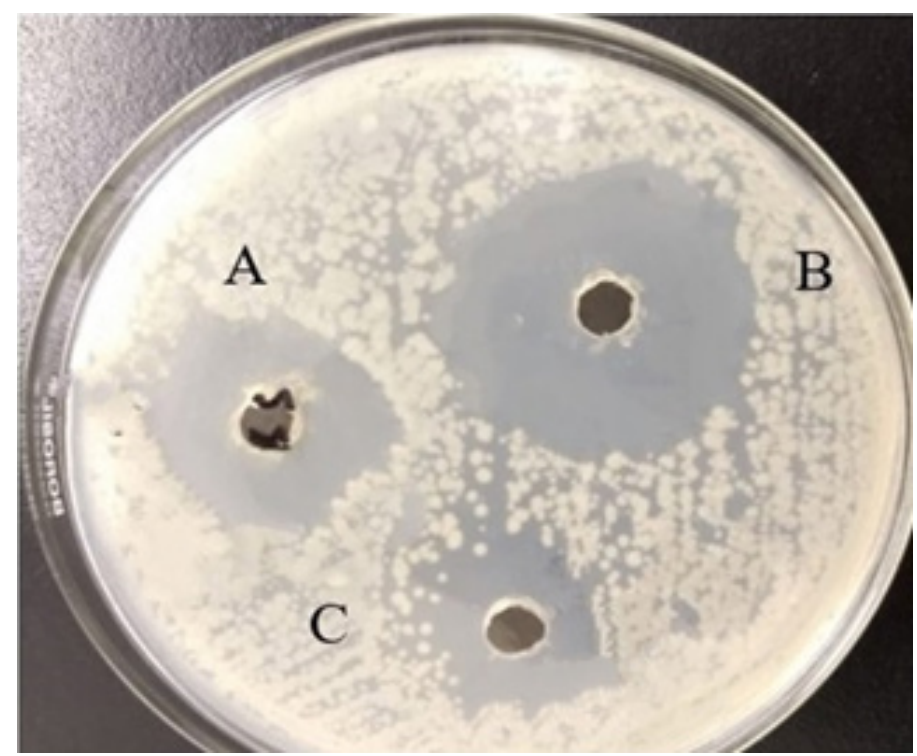

Figure 5: Anti-shrimp pathogen activity using A) Biosurfactant alone B) Pyocyanin and Biosurfactant C) Pyocyanin alone. The analysis were carried out in triplicate.

a

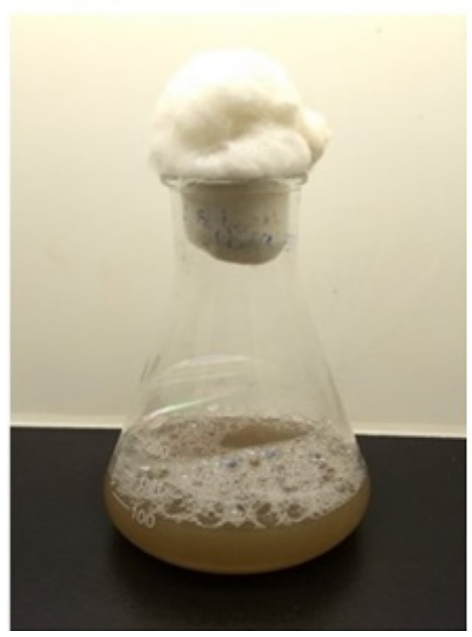

Supple Figure 1: (a) Foam formation confirming the production of biosurfactant in LB broth. (b) Green pigmentation confirming the production of pyocyanin in LB broth.

enhanced when the biosurfactant was tested in union with pyocyanin pigment. The zone of clearance was $0.8 \pm 0.03,0.6 \pm 0.05,1.2 \pm 0.1$ $\mathrm{cm}$ when biosurfactant alone, pyocyanin alone and biosurfactant and pyocyanin were tested respectively (Figure 5).

\section{DISCUSSION}

Glucose is the preferential source of carbon for biosurfactant production. $^{28,29}$ As predicted there was higher production of biosurfactant when $\mathrm{BHB}+1 \%$ Glucose (Figure $1 \mathrm{~b}$ ) was used as a carbon source $(9.23 \pm 0.38 \mathrm{mg} / \mathrm{ml})$. Previous studies using BushnellHaas medium supplemented with $1 \%$ Glucose, Varjani and Vivek have reported biosurfactant yield of about 3.178 $\pm 0.071 \mathrm{~g} / \mathrm{l}$ at $96 \mathrm{~h} .^{30}$ Moreover, various studies have recorded the use of glucose as carbon source in the production of biosurfactant from Pseudomonas aeruginosa
Table 1: Oil recovery by Sand Pack Column (OOIP stands for Original Oil in Place, BS stands for Biosurfactant). All the analysis were carried out in triplicate. The values were presented as mean \pm SD $(n=3)$

\begin{tabular}{ccccc}
\hline OOIP $(\mathrm{ml})$ & \multicolumn{2}{c}{ BS flooding } & \multicolumn{2}{c}{ BS and Pyocyanin flooding } \\
\hline & \multicolumn{2}{c}{ Recovery } & \multicolumn{2}{c}{ Recovery } \\
25 & $\mathrm{ml}$ & OOIP\% & $\mathrm{ml}$ & OOIP\% \\
\hline
\end{tabular}

and has reported a yield of 1.0-1.6g/l. ${ }^{31-33}$ Also, LB broth was assessed for biosurfactant concentration and the yield harvested by LB broth (Supplementary Figure 1a) at $48 \mathrm{~h}(11.07 \pm 0.15 \mathrm{mg} / \mathrm{ml})$ was higher than that of Bushnell Haas medium supplemented with 1\% Glucose (Figure 1b). Although using economical carbon sources Mukherjee et al. have reported biosurfactant yield of $45 \mathrm{~g} / \mathrm{l}^{34}$ Thus this study reports the highest concentration of biosurfactant reported using glucose as a sole carbon source and Luria Bertani Broth was ascertained for biosurfactant production as it gave a higher yield.

Pseudomonas aeruginosa strains isolated from rice cultivated field, clinical specimen (Urinary tract infection) and agricultural soil have been reported to produce a yield of $9.3,5.5,2.56 \mu \mathrm{g} / \mathrm{ml}$ respectively. ${ }^{26,35}$ Thus, the higher concentration of pyocyanin at static condition was ascertained for the production of pyocyanin pigment. To the best of our knowledge this is the highest yield of pyocyanin produced by Pseudomonas aeruginosa.

As the cell free supernatant emulsified oils like sunflower, groundnut, gingelly, castor and almond oil, it can be utilized as bio-emulsifiers in the food industries. ${ }^{4}$ The biosurfactant produced from Pseudomonas aeruginosa using Luria-Broth demonstrated high emulsification activity with kerosene (70\%). ${ }^{33,36}$ Also, Al Wahaibi et al. has reported $50 \%$ of crude oil emulsification with less biosurfactant production $(0.5 \mathrm{~g} / \mathrm{ml})$ by Bacillus subtilis B30. ${ }^{37}$ Similarly, Dastgheib et al. have reported 65\% of crude oil emulsification by Bacillus strains. ${ }^{38}$ Moreover, a striking observation was made during the study, partial emulsification of hydrocarbons (crude oil, petrol and kerosene) was observed when biosurfactant alone was tested, whereas complete emulsification of hydrocarbons was observed when Pyocyanin and Biosurfactant administered simultaneously. Palshpriya Das and Luyan ${ }^{14}$ have reported the assistance of pyocyanin in biosurfactant mediated hydrocarbon emulsification. Thus, we hypothesized that pyocyanin should also aid in biosurfactant mediated oil recovery which was tested following the emulsification study. Various literature has been documented on the potential applicability of biosurfactants for oil recovery. ${ }^{39-42}$

The experiment conducted by Asha Dhasayan ${ }^{23}$ using MB 30 recovered $62 \%$ of crude oil from the sand pack column at room temperature. Further studies by Bordoloi and Konwar ${ }^{19}$ using biosurfactant removed $60 \%$ of crude oil at room temperature and an additional 15\% recovery at $90^{\circ} \mathrm{C}$. As an extension of the hydrocarbon emulsification study, ${ }^{14}$ the current study highlights the novel assistance of pyocyanin in biosurfactant mediated oil recovery. It may be due to the tremendous concentration of pyocyanin produced by Pseudomonas aeruginosa ENO-14 that can be attributed as a survival strategy as the cooperation of pyocyanin and biosurfactant results in enhanced wettability alteration of hydrocarbons in the oil-contaminated source. ${ }^{43}$ Also, the production of biosurfactant was maximum in the initial days (48 h) (Figure 1a) followed by the maximum production of Pyocyanin (Figure 2a) at later stages that might assist the activity of biosurfactant. The majority of biosurfactants produced by Pseudomonas strains have applicability in bioremediation and as antimicrobial agents, quite a few reports have demonstrated their applicability in the oil recovery process. ${ }^{42,44}$ Various 
studies have verified the applicability of biosurfactants in residual oil recovery at sublime salinities and temperature, especially rhamnolipids have a higher effective concentration than other biosurfactants like lipopeptides. ${ }^{45}$

Moreover, futuristic productivity of MEOR technology can be benefitted by such a combinatorial role played by pyocyanin as determined by a compelling increase in the amount $(15 \%)$ of oil recovered when pyocyanin was administered harmoniously along with biosurfactant. Such coupling increases the credibility and efficiency of MEOR process. The performance of the potential biosurfactant extracted from the highly efficient Pseudomonas aeruginosa can be assessed by either sand pack column model or core flood experiments, the latter being used widely in pilot-scale or on field experiments and the former confirms the efficiency at a laboratory scale. ${ }^{18-19,42}$ Although converting this laboratory scale success uphill for pilot scale and on the field requires further studies and understanding.

The independent role of biosurfactant and redox active pyocyanin as antibacterial agents against potential pathogens has been widely accepted and reported. ${ }^{7-9,35}$ In this study, Biosurfactant showed activity against Vibrio parahemolyticus (shrimp pathogen) and presented a synergistic effect when combined with pyocyanin. Even with directed toxicity by pyocyanin from clinical isolates, environmental isolates could be used against vibriosis in aquaculture as a drug of choice. ${ }^{46}$

\section{CONCLUSION}

Biosurfactant and pyocyanin were produced by Pseudomonas aeruginosa ENO-14. Biosurfactant and pyocyanin concentration differed with the media used and with the condition (Static or shaking) respectively. The highest concentration of pyocyanin was recorded and their assistance in biosurfactant mediated oil emulsification, oil recovery and against shrimp pathogen Vibrio parahemolyticus were validated. This pioneer coupled demonstration of pyocyanin and biosurfactant can be further studied and utilized to combat environmental issues such as oil spills and for the betterment of shrimp farming.

\section{CONFLICT OF INTEREST}

All the authors declare that there is no conflict of interest.

\section{ABBREVIATIONS}

LB: Luria Bertani; UV: Ultraviolet; HCl: Hydrochloric acid; O.D: Optical density; NaCl: Sodium chloride; BHB: Bushnell Haas broth, MEOR: Microbial enhanced oil recovery.

\section{REFERENCES}

1. Silva RDCFS, Almeida DG, Rufino RD, Luna JM, Santos VA, Sarubbo LA, et al. Applications of biosurfactant in the petroleum industry and the remediation of oil spills. Int J Mol Sci. 2014;15(7):12523-42.

2. Souza EC, DeSouza ORP, Vessoni-Penna TC. Biosurfactant-enhanced hydrocarbon bioremediation: An overview. Int Biodeterior Biodegrad. 2014;89:88-94

3. Santos DK, Rufino RD, Luna JM, Santos VA, Sarubbo LA. Biosurfactant: multifunctional biomolecules of the $21^{\text {st }}$ century. Int J Mol Sci. 2016;17(3):401.

4. Satek K, Euston SR. Sustainable microbial biosurfactant and bioemulsifiers for commercial exploitation. Process Biochem. 2019;85:143-55.

5. Safdel M, Anbaz MA, Daryasafar A, Jamialahmadi M. Microbial enhanced oil recovery, a critical review on worldwide implemented field trials in different countries. Renew Sust Ener Rev. 2017;74:159-72.

6. Benincasa M, Abalos A, Oliveira I, Manresa A. Chemical structure, surface properties and biological activities of the biosurfactant produced by Pseudomonas aeruginosa LBI from soapstock. Antonie Van Leeuwenhoek. 2004;85(1):1-8.

7. Haba E, Pinazo A, Jauregui O, Espuny MJ, Infante MR, Manresa A. Physicochemical characterization and antimicrobial properties of biosurfactant produced by Pseudomonas aeruginosa 47T2 NCBIM 40044. Biotechnol Bioeng. 2003;81(3):16-322.
8. Blankenfeldt W, Parsons JF. The structural biology of phenazine biosynthesis. Curr Opin Struct Biol. 2014;29:26-33.

9. Baron SS, Rowe JJ. Antibiotic action of pyocyanin. Antimicrob Agents Chemother. 1981;20(6):814-20.

10. Vijayan KK, Singh ISB, Jayaprakash NS, Alavandi SV, Pai SS, Preetha R, et al. A brackish waterisolate of Pseudomonas PS-102, a potential antagonistic bacterium against pathogenic vibrios in penaied and non-penaied rearing systems. Aquaculture. 2006;251(2-4):192-200.

11. Preetha R, Jose S, Prathapan S, Vijayan KK, Jayaprakash NS, Philip R, et al. An inhibitory compound produced by Pseudomonas with effectiveness on Vibrio harveyi. Aquac Res. 2010;41(10):1452-61.

12. Priyaja P, Jayesh P, Correya NS, Sreelakshmi B, Sudheer NS, Philip R, et al. Antagonistic effect of Pseudomonas aeruginosa isolates from various ecological niches on Vibrio species pathogenic to crustaceans. J Coast Life Med. 2014;2(1):76-84

13. Pai SS, Anas AA, Jayaprakash NS, Priyaja P, Sreelakshmi B, Philip R, et al. Penaeus monodon larvae can be protected from Vibrio harveyi infection by preemptive treatment of rearing system with antagonistic or non-antagonistic bacterial probiotics. Aquac Res. 2010;41(6):847-60

14. Das P, Ma LZ. Pyocyanin pigment assisting biosurfactant-mediated hydrocarbon emulsification. Int Biodeterior Biodegrad. 2013;85:278-83.

15. Franzetti A, Gandolfi I, Bestetti G, SmythTJ, Banat IM. Production and applications of trehalose lipid biosurfactant. Eur J Lipid Sci Technol. 2010;112(6):617-27.

16. Lin CW, Chen LH, Yet-Pole I, Lai CY. Microbial communities and biodegradation in lab-scale BTEX-contaminated groundwater remediation using an oxygenreleasing reactive barrier. Bioproc Biosyst Eng. 2010;33(3):383-91.

17. Cosse R. Basics of reservoir engineering. Pure and applied geophysics, Editions technip. 1993.

18. Suthar $\mathrm{H}$. Evaluation of bioemulsifier mediated microbial enhanced oil recovery using a sand packed column. J Microbiol Methods. 2008;75(2):225-30.

19. Bordoy N, Konwar B. Microbial surfactant enhanced mineral oil recovery under laboratory conditions. Colloids Surf B Biointerfaces. 2008;63(1):73-82.

20. Amani H, Mehrnia MR, Haghighi M, Sarrafzadeh MH, Soudi MR. Scale up and application of biosurfactant from Bacillus subtilis in enhanced oil recovery. Appl Biochem Biotechnol. 2010;162(2):510-23.

21. Amani H, Sarrafzadeh $M H$, Haghighi M, Mehrnia MR. Comparative study of biosurfactant producing bacteria in MEOR applications. J Petrol Sci Eng. 2010;75(1-2):209-14

22. Abu-Ruwaida AS, Banat IM, Haditirto S, Salem A, Kadri M. Isolation of biosurfactant producing bacteria, product characterization and evaluation. Acta Biotechnologica. 1991;11(4):315-24.

23. Dhasayan A, Kiran GS, Selvin J. Production and characterisation of glycolipid biosurfactant by Halomonas sp. MB-30 for potential application in enhanced oil recovery. Appl Biochem Biotechnol. 2014;174(7):2571-84

24. Saha S, Thavasi R, Jayalakshmi S. Phenazine pigments from Pseudomonas aeruginosa and their application as antibacterial agent and food colourants. Res J Microbiol. 2008;3(3):122-8.

25. Essar DW, Eberly L, Hadero A, Crawford IP. Identification and characterization of genes for a second anthranilate synthase in Pseudomonas aeruginosa: Interchangeability of the two anthranilate synthases and evolutionary implications. J Bacteriol. 1990;172(2):884-900.

26. El-Fouly MZ, Sharaf AM, Shahin AA, El-Bialy HA, Omara AM. Biosynthesis of pyocyanin pigment by Pseudomonas aeruginosa. J Radiat Res Appl Sci. 2015;8(1):36-48.

27. Nitschke M, Pastore GM. Biosurfactant production by Bacillus subtilis using cassava-processing effluent. Appl Biochem Biotechnol. 2004;112(3):163-72

28. Batista SB, Mounteer AH, Amorim FR, Totola MR. Isolation and characterization of biosurfactant/bioemulsifier-producing bacteria from petroleum contaminated sites. Bioresour Technol. 2006;97(6):868-75.

29. Nurfarahin AH, Mohamed MS, Phang LY. Culture medium development for microbial-derived surfactants production: An overview. Molecules. 2018;23(5):1049.

30. Varjani SJ, Upasani VN. Carbon spectrum utilization by an indigenous strain of Pseudomonas aeruginosa NCIM 5514: Production, characterization and surface active properties of biosurfactant. Bioresour Technol. 2016;221:510-625.

31. Sim L, Ward OP, Li ZY. Production and characterisation of a biosurfactant isolated from Pseudomonas aeruginosa UW-1. J Ind Microbiol Biotechnol. 1997; 19(4):232-8

32. Guerra-Santos L, Kappeli O, Fiechter A. Pseudomonas aeruginosa biosurfactant production in continuous culture with glucose as carbon source. Appl Environ Microbiol. 1984;48(2):301-5.

33. Ehinmitola EO, Aransiola EF, Adeagbo OP. Comparative study of various carbon sources on rhamnolipid production. S Afr J Chem Eng. 2018;26:42-8.

34. Mukherjee S, Das P, Sen R. Towards commercial production of microbial surfactants. Trends Biotechnol. 2006;24(11):509-15.

35. DeBritto S, Gajbar TD, Satapute P, Sundaram L, Lakshmikantha RY, Jogaiah $\mathrm{S}$, et al. Isolation and characterization of nutrient dependent pyocyanin from Pseudomonas aeruginosa and its dye and agrochemical properties. Scientific 
Reports. 2020;10(1):1-2.

36. Lovaglio RB, DosSantos FJ, Junior MJ, Contiero J. Biosurfactant emulsifying activity and emulsion stability: $\mathrm{pH}$ rules. Colloids Surf B: Biointerfaces. 2011;85(2):301-5.

37. Al-Wahaibi Y, Joshi S, Al-Bahry S, Elshafie A, Al-Bemani A, Shibulal B. Biosurfactant production by Bacillus subtilis B30 and its application in enhancing oil recovery. Colloids Surf B Biointerfaces. 2014;114:324-33.

38. Dastgheib SM, Amoozegar MA, Elahi E, Asad S, Banat IM. Bioemulsifier production by a halothermophilic Bacillus strain with potential applications in microbially enhanced oil recovery. Biotechnol Lett. 2008;30(2):263-70.

39. Gudina EJ, Pereira JF, Costa R, Coutinho JA, Teixeira JA, Rodrigues LR Biosurfactant-producing and oil-degrading Bacillus subtilis strains enhance oil recovery in laboratory sand-pack columns. J Hazard Mater. 2013;261:106-13.

40. Sharma R, Singh J, Verma N. Optimization of biosurfactant production from Pseudomonas aeruginosa PBS towards application for microbial enhanced oil recovery. 3 Biotech. 2018;8(1):20.

41. Ali N, Wang F, Xu B, Safdar B, Ullah A, Naveed M, et al. Production and Application of Biosurfactant Produced by Bacillus licheniformis Ali5 in Enhanced
Oil Recovery and Motor Oil Removal from Contaminated Sand. Molecules. 2019;24(24):4448.

42. Elakkiya VT, Suresh KP, Alharbi NS, Kadaikunnan S, Khaled JM, Govindarajan M. Swift production of rhamnolipid biosurfactant, biopolymer and synthesis of biosurfactant-wrapped silver nanoparticles and its enhanced oil recovery. Saudi J Biol Sci. 2020;27(7):1892-9.

43. Aparna A, Srinikethan G, Hedge S. Effect of addition of biosurfactant produced by Pseudomonas ssp. on biodegradation of crude oil. Int Proc Chem Biol Environ Eng. 2011;6:71-5.

44. Amani H, Muller MM, Syldatk CX, Hausmann R. Production of microbial biosurfactant by Pseudomonas aeruginosa MM1011 for ex situ enhanced oil recovery. Appl Biochem Biotechnol. 2013;170(5):1080-93.

45. Wang Q, Fang X, Bai B, Liang X, Shuler PJ, Goddard WA, et al. Engineering bacteria for production of biosurfactant as an agent for enhanced oil recovery. Biotechnol Bioeng. 2007:98(4):842-53.

46. Priyaja P, Jayesh P, Philip R, Singh IB. Pyocyanin induced in vitro oxidative damage and its toxicity level in human, fish and insect cell lines for its selective biological applications. Cytotechnol. 2016;68(1):143-55.

Article History: Submission Date : 12-09-2020; Revised Date : 07-10-2020; Acceptance Date : 25-10-2020.

Cite this article: Shankar S, Haque E, Hassan S. Pyocyanin Assisting Biosurfactant Mediated Anti-shrimp Pathogen Activity and Crude Oil Recovery. Int. J. Pharm. Investigation, 2020;10(4):575-80. 